\title{
AVALOVARA: UMA COSMOGONIA LITERÁRIA
}

\author{
Leny da Silva Gomes
}

RESUMO: This essay presents Osman Lins' novel, Avalovara. The complex structure of this work is here highlighted, related to the Pitagoras'geometric and mathematical forms, the symbolic language associated with the hermetical, intertextual references and myths, the palindrome, the spiral and the square, that compose, among other elements, this intense story of love and knowledge.

PALAVRAS-CHAVE: Avalovara, palíndromo, espiral, formas matemático-geométricas.

Osman Lins tem uma obra rica, complexa, inovadora e, paradoxalmente, desprivilegiada no espaço literário brasileiro. Sua produção, abrangendo romances, contos, peças teatrais e ensaios críticos, situa-se no período que vai de 1950 a 1977. Quando morreu, em 1978, escrevia A cabeça levada em triunfo, romance inacabado que teve trechos selecionados por Julieta de Godoy Ladeira, esposa do escritor, e publicados na Revista do Instituto de Estudos Brasileiros (USP), n.38, 1995.

Perguntarmo-nos o porquê de sua estranha posição no cânone brasileiro, já que seus méritos literários e sua originalidade são reconhecidos, pode nos levar a uma série de hipóteses, cuja confirmação necessariamente levaria a um longo debate. Dada a natureza deste texto, originalmente uma comunicação oral, opto por fazer uma apresentação de Avalovara, talvez a obra mais importante do Autor, e, concomitantemente, apontar alguns elementos que criam obstáculos à sua compreensão numa primeira leitura. Meu interesse é, portanto, tornar menos desconhecida essa obra, para que ela, talvez, conquiste alguns leitores.

Por que esse romance, que narra uma história de amor numa linguagem clara, provoca constantes suspensões da fluidez da leitura, fazendo com que o leitor vá e volte, muitas vezes interrompendo seu ato de ler? Uma resposta preliminar e abrangente está relacionada à complexidade da sua composição, à desafiadora multiplicidade de

Leny da Silva Gomes é professora do Curso de Letras da Faculdade de Educação, Ciências e Letras Ritter dos Reis.

Título da tese de doutorado, defendida em 1998, na Universidade Federal do Rio Grande do Sul. 
veladas referências inter-textuais (não apenas de textos escritos, mas em um amplo sentido), à sua linguagem simbólica e ao uso original de uma forma gráfica na identificação de uma das personagens. Esses aspectos dão testemunho do percurso literário do Autor e de sua problematizadora forma de expressão, que se coloca entre o caos e o cosmo. Não por acaso, uma das figuras emblemáticas de Avalovara é Jano, divindade latina, protetora dos limiares, que com seu duplo rosto, um voltado para a frente e outro para trás, representa a capacidade de ver simultaneamente o passado e o futuro, estando ligada à ordem e à desordem.

A composição geométrica, matematicamente calculada, as referências cifradas, a nomeação das personagens e a recriação, nos limites de um livro, do ilimitado e movente mundo das representações são conscientemente elaboradas no reverso do racionalismo binário próprio de nosso pensamento. Segundo palavras do próprio Autor, é a aproximação com o leitor que avulta nessa intrincada elaboração:

"Não resumo Avalovara; seria a mesma coisa que contar um sonho: ele perde a metade do valor, porque as idéias confusas ganham uma certa clareza que não existe no nosso inconsciente. A obra ficaria incompreensível, e o resultado seria o oposto de tudo que tentei fazer nesses três anos, escrever para o leitor sem perder contato com ele em momento algum" (LINS, 1979, p. 171).

Dessa declaração dois dados nos chamam a atenção: o que diz respeito à clareza das idéias confusas e o que se refere ao contato permanente com o leitor. Parecem estranhas essas duas direções, pois com freqüência Avalovara tem sido apontado pela crítica como um texto difícil, hermético, portanto um texto que afasta, que perde o contato com o leitor, pelos obstáculos que interpõe a uma leitura fluente, tranqüilizadora. Ao contrário de Machado de Assis, cuja forma de advertir o leitor nos é familiar, Osman Lins não dissimula a complexidade de sua criação/construção, cujas inovações ultrapassam a simples desautomatização da leitura, indo, talvez, além das possibilidades do leitor de fruir e de compreender o texto desimpedido de questionamentos, sem discussão e amadurecimento das idéias - embora seja possível também uma leitura conduzida pelo ritmo poético da prosa, por sua linguagem plástica, pelos jogos metafóricos, pelos cortes e retomadas que ora instigam o leitor ora o confundem, pela linguagem erótica que identifica o corpo textual e o corpo das personagens. O desejo do leitor da busca do sentido e o desejo do Autor de comunicação, de encontrar no leitor um parceiro de sua trajetória, servem-se do método da interrogação, instaurando na linguagem um campo erótico, entendido em seu sentido de falta, de carência, que demanda a busca do outro.

Esse inquietante deslocamento de uma leitura a outra torna-se uma forma de contato constante com o leitor, que, durante todo o percurso, é obrigado a questionarse, refletir sobre o que é sugerido e tentar colaborar com o Autor na reconstrução da teia romanesca. Um exemplo desse processo já nos é dado ao abrimos o livro. No verso da folha que contém as cinco epígrafes, vemos uma estranha superposição de uma espiral e um quadrado subdividido em 25 pequenos quadrados, contendo cada 
um deles uma letra do palíndromo SATOR AREPO TENET OPERA ROTAS. A frase, que pode ser lida em qualquer direção mantendo-se inalterada, provoca uma série de perguntas: qual sua significação? qual sua funcionalidade como elemento paratextual? qual sua origem e qual sua relação com a composição de Avalovara? O quadrado, agregado ao palíndromo, transforma-se de simples forma geométrica em Quadrado Mágico ${ }^{1}$ e faz ressurgir, na linguagem do romance, um substrato sagrado e de magia.

Embora o Autor nos esclareça logo no início dos primeiros capítulos que a composição do romance segue os giros da espiral sobre as oito letras do palíndromo ( R, S, A, O, T, P, E, N) e que a cada letra corresponde um tema, no processo da leitura percebemos que há repetições de frases, imagens, cenas e personagens, gerando deslocamentos que transformam a montagem, que seria de um entrelaçamento conforme a circularidade da espiral, em uma série de imbricações, como se a grande espiral do todo contivesse muitas outras espirais que se movimentam enlaçando os elementos da obra de maneira tal que seja perceptível uma analogia entre as partes e o todo. Esse modo de compor é significativo na relação dos planos físico e metafísico, na integração do homem com o cosmo, no posicionamento da literatura brasileira em face da literatura universal e na produção da modernidade ligada às raízes de antigos mitos cosmogônicos, num infindável movimento espiralado.

Nos ensinamentos pitagórico-platônicos a simetria é o resultado da justa proporção das partes entre si e destas com o todo. A espiral logarítmica representa esse princípio da harmonia, resultante da simetria, pois embora seu crescimento seja terminal a forma permanece sempre a mesma, em qualquer estágio. Transpondo esse movimento para o romance, Osman Lins constrói uma narrativa em que pequenas unidades dispersas no todo mantêm relações entre si e com o romance em sua totalidade. Essas unidades se constituem em emblemas, micronarrativas, símbolos e alegorias representadas por surpreendentes e variadas formas. Assim, temos no conjunto de formas geométricas e palíndromo a visualização da força motriz do romance e sua armação geométrica que se estende ao sagrado.

A ordenação de Avalovara obedece a dois planos inter-relacionados: um, baseado no rigor matemático-geométrico de origem pitagórica, que atribui aos números um valor simbólico não quantitativo, mas relacional, abrangendo a natureza, $o$ humano e o sagrado; outro, baseado na captação do imaginário, do substrato mítico e artístico de nossa civilização. A analogia entre a ordem do universo e a ordem do romance remete à sacralização das criações humanas, sem perder de vista as coerções sociais:

"Presidem este encontro o signo da escuridão - símile de insciência e do caos - e o signo da confluência: germe do cosmos e evocador da ordenação mental. Terra, espaço, Lua, movimento, Sol e tempo preparam a conjugação da simetria e das trevas "(LINS, 1974, R 7, p. 36).

${ }^{1}$ Essa denominação é usada por Osman Lins, embora o palíndromo seja identificado por várias outras: quadrado ou retângulo mágico cristão, fórmula profilática cristã, amuleto místico, rebus sator etc. 
A captação do movimento, do fluir da vida, da finitude humana, expressa o desejo do homem de unidade e de perenidade. A mobilidade do mundo e a imutabilidade do divino, evocadas nas formas geométricas relacionadas ao palíndromo, são representadas em Avalovara também por figuras míticas: Hermes (o condutor das almas), Jano (deus do limiar entre o caos e cosmo), Tyche (distribuidora da fortuna, manipuladora do destino). A divindade hindu Avalokiteshvara ${ }^{2}$, origem do título Avalovara, permanece entre a terra e o céu por sentir compaixão pelos homens, apesar de já ter atingido o conhecimento, que a habilita ao Nirvana. O texto refere-se ao avalovara como um pássaro, cuja simbologia pode estabelecer interessante elo com a divindade Oriental, indicando uma perspectiva de leitura.

Voltando à declaração do autor e à sua negativa em resumir o romance, verificamos que sua resistência coincide com a do leitor-crítico que protela em responder à pergunta primeira de potenciais leitores: mas, afinal, de que trata a obra? Uma resposta formalizada, construída após anos de estudo, é: a obra trata do amor, do conhecimento e do sagrado, formando uma unidade temática, expressa já no título AVA/LOV/ARA e ordenada por padrões geométricos, numerais e simbólicos. Uma resposta no nível da história narrada - com a qual, repetindo o Autor, perde-se a metade do valor da obra - pode ser elaborada levando-se em consideração a trajetória de Abel, um jovem escritor em busca do constante aperfeiçoamento, e do seu amor pelas três personagens: Anneliese Roos - européia, colega de Abel na Aliança Francesa em Paris, que se mantém em constante mobilidade entre o estudo, o trabalho, as viagens e o atendimento a seu marido doente; Cecília - a nordestina andrógina que percorre com Abel uma trajetória de amor e morte; e $]^{3}$ - confluência dos amores precedentes e encontro decisivo de Abel. Cada uma dessas personagens tem algum atributo inusitado. Anneliese Roos tem seu corpo formado por cidades, ou seja, Abel vê em Roos a imagem de cidades, quando ele próprio sonha e busca uma cidade, alegoria de sua busca da criação da obra literária, que se tornará concomitante realização de seu trajeto individual de conhecimento e de autoconhecimento. A andrógina Cecília tem seu corpo habitado por homens, mulheres, crianças e animais que transitam silenciosos para os espaços circundantes, de forma autônoma, sem interferir nas ações do casal. A personagem $\square$ é formada de letras, sons e palavras e mantém com Abel uma relação inicialmente marcada por furtivos encontros, que são etapas prepa-

${ }^{2} \mathrm{~A}$ leitura de textos críticos e das entrevistas do Autor revela: "Pensava guardar para mim o segredo, mas revelo-o. Há uma divindade oriental, um ser cósmico, de cujos olhos nasceram o Sol e a Lua; de sua boca, os ventos; de seus pés, a Terra. Assim por diante. É lâmpada para os cegos, água para os sedentos, pai e mãe dos infelizes. Tem muitos braços, pois não lhe falta trabalho no mundo. Seu nome é Avalokiteçvara (sic). Não foi difícil, aproveitando esse nome, chegar ao nome claro e simétrico de 'Avalovara', que muitas pessoas acham estranho" (LINS, 1979, p. 165).

${ }^{3}$ Nos manuscritos do Autor, encontra-se o desvelamento do significado dessa forma de nomeação da personagem (um círculo com um ponto central e dois traços externos como duas hastes ou um par de asas): " $\square$ 'nome' da principal personagem feminina. $O$ sinal funde 2 símbolos: o da Trindade e o do ouro alquímico". 
ratórias para o amadurecimento e decisão do encontro final, em que são obviamente surpreendidos pelo marido de $\square$ que os mata: "Transitamos entre nós, vamos de mim a mim eu eu nós eu eu de mim a mim, laço e oito, boca e boca, transitamos e somos, a esfera circunscreve-nos e nós próprios uma esfera, boca e boca (de quem?)" (LINS, 1974, N 2, p. 408). Assim resumido e levando em consideração o erotismo das cenas e da linguagem, poderíamos dizer que o texto não passa de mais um romance licencioso. Porém a trajetória amorosa de Abel mantém outras relações, transcende o plano físico, tornando-se mediação entre o conhecimento e o sagrado. Revivendo o Eros platônico, o amor em Avalovara transita da beleza física à beleza de todos os corpos e desta à verdadeira Beleza. $\mathrm{O}$ amor, a palavra poética, a memória e a imaginação são fios que tecem o sonho de eternidade e a nostalgia do Paraíso, este simbolizado pelo tapete sobre o qual Abel e $\mathrm{C}$ amam e morrem:

"novo relâmpago na sala e ouvimos irado cheio de dentes irados o ladrar dos cães e cruzamos um limite e nos integramos no tapete somos tecidos no tapete eu e eu margens de um rio claro murmurante povoado de peixes e de vozes nós e as mariposas nós e girassóis nós e o pássaro benévolo mais e mais distantes latidos dos cachorros vem um silêncio novo e luminoso vem a paz e nada nos atinge, nada, passeamos, ditosos, enlaçados, entre os animais e plantas do Jardim". (LINS, 1974, N 2, p. 413).

A percepção da relação do homem com o sublime é expressa numa linguagem simbólica e no processo auto-reflexivo do romance, no constante construir e questionar seu próprio fazer, desnudando-se enquanto processo ficcional e de maturação do escritor, de conquista do conhecimento. $\mathrm{O}$ amor é signo da carência e da mediação na busca da plenitude. Nesse sentido é o condutor de Abel, através das figuras femininas. O protagonista percorre uma trajetória que vai da insciência, quando ainda menino deita-se à beira da cisterna, à busca da Cidade na Europa, quando jovem, e, de volta ao Recife, ao encontro de Cecília. Essa personagem andrógina é a condutora que o levará a superar um limite:

"Urros apagados de leões. Chamo-a ainda uma vez, mas este chamado já é pobre de convicção, embora eu não queira, não possa admitir que Cecília, macho-fêmea, força e compaixão, doadora e beneficiária, Cecília, esteja morta. (...) De súbito, atravesso um pórtico, um limite”. (LINS, 1974, T 17, p. 312).

Com a morte de Cecília Abel inicia nova fase junto a $[$. Essa personagem mais do que as outras duas está relacionada aos textos: "percebo-me inundada, povoada de vozes, vozes no meu sangue, nas costelas, nos maxilares, nos cabelos, nos olhos, nas unhas, muitas vozes" (LINS, 1974, O 15, p. 136). Abel, ao mesmo tempo que vai descobrindo o corpo de sua amante, descobre as palavras, as vozes que soam de longe, representação não só de Anneliese Roos e Cecília enquanto personagens, mas principalmente enquanto alegorias; a primeira, de uma cultura universal, simbolizada nas Cidades que flutuam em seu corpo, e a segunda como representação do povo nordestino, da nossa memória, da carência individual e coletiva e da sacralidade do ato criador. O percurso de Abel na Europa à procura da Cidade e do amor de Roos 
traz para o tema A (Roos e as Cidades), amalgamadas no texto, figuras representativas da cultura universal, oriundas das produções artísticas que formam um substrato sem fronteiras. Desta forma temos a presença de Dante, de Rabelais, Dostoieveski, Catullo, Anacreonte, Virgílio, Isidoro de Sevilha, Cassiodoro, Papa Silvestre II, Scarlatti, Mozart, Carl Orff, Rembrandt, Masaccio, Palladio, Aldo Manuzio, construções como o Castelo de Chambord, entre outros. Assim, a captação do imaginário conjuga-se à formalização de base pitagórica que, ao colocar em analogia as partes e o todo, faz de Avalovara uma cosmogonia literária que absorve e ordena um trajeto histórico-cultural- literário disperso no oceano turvo de nossa memória.

Se a música de Orff traz ao texto os apaixonados e eróticos poemas de Catulo, dirigidos a sua amante Hipsitila, os encontros e desencontros do tema A, ao contrário, evocam no apelativo "Príncipe Mitchkin" a desencontrada busca de um amor sempre inatingido, enquanto $\square$, união das três personagens femininas, é identificada com Sulamita do Cântico dos Cânticos, poema bíblico erótico, sagração do amor. A caridosa Cecília em sua relação com Abel é emoldurada por animais, pelo poema Le Lac e por $O$ Aleph, num prenúncio de sua unidade primordial, de sua morte e de seu poder renovador.

O processo alquímico da transmutação é a fonte e a chave para a compreensão da evolução de Abel, da transformação da luminosa Cecília, da presença do unicórnio "que circula entre estas páginas", da transformação de leões negros - os quais acompanham Cecília em seus primeiros encontros com Abel - em leões verdes, quando o destino, representado por um cabriolé, a conduz para a morte. Hermeticamente representadas, algumas figuras passam despercebidas, algumas situações parecem insignificantes, apagadas em relação à exuberância de outras situações e personagens. É o caso da personagem Cara de Calo, das irmãs Hermelinda e Hermenilda, das figuras Ser e Não-Ser, da presença dos animais, da androginização de Abel, da transformação de Cecília em vítima sacrificial, da função da cisterna, do paralelo entre a visibilidade da posição dos astros no momento do eclipse e o mapa das viagens de Abel em busca da Cidade, da queda e renascimento de $\square$ (nascida e nascida). Embora a trajetória mais marcante e naturalmente mais desenvolvida seja a do protagonista Abel, que podemos acompanhar e descrever como um processo de transmutação, outras trajetórias realizam-se marcadas pelos princípios alquímicos e pela frase hermética atribuída a Hermes Trismegisto: "O que está embaixo é como o que está em cima, e o que está em cima é como o que está embaixo; por essas várias coisas se fazem os milagres de uma só coisa". Respondem a esta interação do um no todo discretas representações que identificamos como sendo figuras das cartas do Tarô. Elas acompanham, sinalizam a representação da evolução de Abel e Cecília e fazem a ligação entre alguns capítulos, mantendo a unidade na dispersão.

Nesse sentido, é perceptível uma linha condutora que enlaça no romance várias perspectivas da temática amorosa, também representadas através de alusões ou de referências explícitas a diferentes textos, como o de Anacreonte, que tem no A 6 
(p.44) a transcrição (recriação) de alguns versos. Os poemas anacreônticos e o fundo musical do Catulli Carmina traçam uma das linhas - dimensão concreta, física, do amor -, paralela à dimensão ideal, representada, no texto, pelo amor entre Abel e Anneliese Roos. Essas linhas convergem para as relações sexuais, rítmica e minuciosamente representadas, descritas sem eufemismos, incorporando à tradição literária brasileira uma consciência do ato criador enquanto corpo e palavra. Osman Lins abre uma nova perspectiva para a temática amorosa, recuperando alguns traços, existentes na literatura universal, da representação do encontro de dois corpos que se fundem num enlace aparentemente infindável, captando, entretanto, o sublime de um instante. Nesse sentido, é esclarecedora a seguinte anotação do Autor:

"Uma coisa que não devo perder de vista: aqui, o órgão masculino é o poder criador. Criador no sentido artístico. No sentido literário. Sem isto, as palavras, gestos ou pensamentos da mulher ficam no nível de qualquer novela licenciosa. E não é isto que pretendo. $\mathrm{O}$ caráter do romance como representação da aventura de escrever um romance, de produzir um romance, não deve ser esquecido. Não há, no homem, um órgão que produza um romance. $\mathrm{O}$ que produz isto é o seu poder criador, servido pela experiência vivida e pela imaginação. Assim, o p. (sic) não é a substituição de outro órgão, a representação carnal de outro órgão carnal. Ele é o signo, a representação visível da força criadora, do poder criador. Ora, para que o poder criador se manifeste, precisa ser estimulado. Ser usado sem estímulo é uma prostituição. O que o estimula? Os sentidos e a reflexão. Os sentidos do homem são estimulados por essa mulher. A cópula é uma obra. Mas a energia criadora do homem é provocada por essa mulher e se dirige a ela (manuscritos microfilmados)". ${ }^{4}$

Essa concepção do fazer literário permeado de sensualidade e a visualização do órgão reprodutor masculino como signo do poder criador, motivado pela mulher, são indícios de uma representação em que jubilosas uniões carnais do plano físico conotam também outras uniões.

Com $\square$ realiza-se a unificação do amor, do conhecimento e do sagrado, cuja culminância é a cópula. [ - texto, realização apaixonada, sobrepõe códigos diferentes e épocas diversas, aglutina, além de diferentes textos da história literária e de representações da cultura ocidental, uma tradição milenar representada na linguagem hermética, que remonta ao deus egípcio Thoth, criador da escrita, associado no pensamento ocidental ao deus Hermes grego, sob o nome de Hermes Trismegisto. Hermes emerge no texto sob as personagens Hermelinda e Hermenilda, fiandeiras que evocam a Moira universal da mitologia grega: "Não nos desvanece a função de conducentes. A agulha, artefato perfurante, fere? Também ajuda a coser. Hermelinda e Hermenilda. Agulhas, nesta fábula fiada pela Morte" (LINS, 1974, T 1, p. 59).

Os símbolos, os movimentos centrífugos e centrípetos, a dispersão e

${ }^{4}$ Os originais de Avalovara e as anotações do Autor foram reproduzidos em microfilme pela Fundação Casa Rui Barbosa (RJ), na qual se encontra parte do acervo de Osman Lins. 
reunificação e a conjugação dos opostos redimensionam a fugacidade da experiência vivida e as inquietações humanas. A circularidade de $\bar{Q}$ e a concepção hermética do movimento circular contínuo revelam que a aparente disposição dos temas conforme a incidência da espiral sobre as letras do palíndromo oculta outros padrões, que são da ordem do entrelaçamento e da contigüidade de início e fim, anulação das distâncias e dos pólos opostos, como no encontro dos corpos dos amantes: "Fim e início. e eu, frente a frente, lado a lado, dorso contra dorso" (E 1, p. 314).

A meticulosa montagem do romance, a engenhosidade e o poder de abertura para o infinito das proporções geométricas fazem de cada parte encaixada o reflexo do todo, indefinidamente, já que cada emblema, micronarrativa ou símbolo terá múltiplas significações e cada leitura poderá estabelecer novas relações. O pássaro avalovara é um dos símbolos deste processo, pois é pássaro feito de pássaros, em seu corpo ouvem-se os zumbidos de abelhas, assim como o texto é construído com inúmeros textos, ecos de poemas, de romances, de dramas que fazem a história literária, tornando-se uma força centrípeta, que num outro movimento da espiral torna-se proliferador de vozes, de imagens, de técnicas narrativas.

O percurso de Abel é a caça à Cidade, a obra concluída, que se realiza seguindo o método dos caçadores, os quais desenvolvem uma habilidade de ler no mundo não apenas o visível mas também as pequenas pistas, de forma que "faces do real que permanecem como que selvagens, abrigadas - pela sua índole secreta - da linguagem e assim do conhecimento" (LINS, 1974, R 14, p. 223) sejam nomeadas e tenham um revelador renascimento.

\section{BIBLIOGRAFIA}

GOMES, Leny da Silva. Avalovara: uma cosmogonia literária. Tese de doutoramento apresentada na Universidade Federal do Rio Grande do Sul, 1998.

LINS, Osman. Avalovara. Apres. Antonio Candido. 2. ed. São Paulo, Melhoramentos, 1974.

.Evangelho na taba: outros problemas inculturais brasileiros. São Paulo, Summus, 1979.

. A cabeça leva em triunfo. In: Revista do Instituto de Estudos Brasileiros. São Paulo, n. 38, 1995, p.227-233. 